\title{
EMPREGABILIDADE DAS PESSOAS COM DEFICIÊNCIA: AVANÇOS E PERSPECTIVAS
}

\author{
Felipe Pedroso dos Santos ${ }^{1}$ \\ Giovana Tognolo Vilela Macedo ${ }^{2}$ \\ Marlisa Ramos De Oliveira ${ }^{3}$
}

\section{Resumo:}

O Brasil é referência na proteção dos direitos da pessoa com deficiência. Há, contundo, uma ausência desses profissionais no mercado de trabalho, seja pela inexistência de cargos condizentes ao acesso por deficientes ou pela baixa qualificação profissional. Nesse sentido, o presente artigo se dispõe a discorrer acerca das dificuldades no acesso das pessoas com deficiência ao meio laboral. Para tanto, será feito uma análise sobre a evolução no tratamento legal e constitucional no que se refere a proteção e inclusão das pessoas com deficiência no mercado, além dos impasses na busca pela igualdade em uma sociedade socialmente desigual.

Palavras-chave: Deficiência; direitos; igualdade; inclusão; qualificação.

\section{EMPLOYABILITY OF PEOPLE WITH DISABILITIES: ADVANCES AND PERSPECTIVES}

\begin{abstract}
:
Brazil is a reference in protecting the rights of people with disabilities. However, there is an absence of these professionals in the market, due to the lack of positions suitable for the disabled or the low qualification of them. So, this article will discuss the difficulty of the access of disables to the labor market. To this end, an analysis will be made on the evolution in legal and constitutional treatment with regard to the protection and inclusion of people with disabilities in the workplace, in addition to the impasses in the search for equality in a socially unequal society.
\end{abstract}

Keywords: Disability; rights; equality; inclusion; qualification.

1. Bacharel em Direito pela Universidade de Taubaté (2017). Mestre em Diretos Econômicos, Sociais e Culturais pelo Centro Universitário Salesiano de São Paulo (2020). Endereço eletrônico: felipe-pedroso @ hotmail.com 2. Bacharel em Direito pelo Centro Universitário Salesiano de São Paulo (1999). Mestranda em em Diretos Econômicos, Sociais e Culturais pelo Centro Universitário Salesiano de São Paulo (2020). Procuradora Jurídica Municipal de Resende/RJ. Endereço eletrônico: giovana_macedo@ hotmail.com

3. Bacharel em Direito pelo Centro Universitário na Microrregião de Osasco (1999). Mestranda em Diretos Econômicos, Sociais e Culturais pelo Centro Universitário Salesiano de São Paulo (2020). Procuradora Jurídica Municipal de Resende/RJ. Endereço eletrônico:maramoso27@gmail.com 


\section{INTRODUÇÃO}

O valor social do trabalho, clausula pétrea presente na Constituição Federal, é considerado um dos pilares fundamentes do Estado Democrático de Direito e juntamente com outros fundamentos de igual valor efetivam o princípio da Dignidade Humana. Atualmente o país possui, segundo o Instituto Brasileiro de Geografia e Estatística (IBGE, 2020), mais de 210 milhões de pessoas, das quais cerca de 6,7\% possuem algum tipo deficiência. As deficiências mais comuns são a deficiência visual $(18,6 \%)$, seguida da motora $(7 \%)$, a auditiva (5,10\%), e, por fim, da deficiência mental (1,40\%) (IBGE, 2017).

O Brasil é referência em políticas públicas inclusivas, criadas para valorizar o indivíduo como parte integrante da sociedade. Conta-se com uma forte estrutura legal direcionada aos interesses da população com deficiência, seja nos campos da saúde, seguridade social e/ou trabalho.

O presente estudo tem por escopo analisar os avanços nas leis de assistência à pessoa com deficiência, as políticas públicas ligadas à criação de emprego e inclusão social, os retrocessos na busca da plena igualdade e os impasses encontrados dentro do mercado de trabalho. Outrossim, serão observados os dados de empregabilidade e os possíveis óbices encontrados na sociedade referentes a inserção da pessoa com deficiência num contexto global. O método utilizado será o bibliográfico em obras de estudiosos das áreas do Direito e das Ciências Sociais, além das leis específicas que regulam o presente tema. Também serão utilizados dados fornecidos pelo Instituto Brasileiro de Geografia e Estatística (IBGE) e pelo Departamento Intersindical de Estatística e Estudos Socioeconômicos (DIEESE).

\section{Definindo conceitos}

A conceituação do termo "pessoa com deficiência" possuiu uma infinidade de entendimentos. Por estar presente nas mais diversas literaturas, o termo acaba sofrendo algumas distorções que acabam por dificultar o entendimento sobre a real delimitação física do indivíduo, bem como o fornecimento de uma definição mais técnica e apropriada para sua abordagem. Na Constituição de 1967, o legislador constitucional se utilizou da "excepcional" para tratar do tema que, por força da Emenda Constitucional $n^{\circ} 12$, recebeu novas garantias, 
mas que não foram levadas a sério, permanecendo à margem dos demais direitos constitucionais.

Àquela época utilizava-se da expressão "pessoa excepcional” para se referir os indivíduos que possuíam algum tipo de deficiência, evoluindo mais tarde, graças a Emenda, para "pessoa portadora com deficiência”, conforme explica, Araújo (2011):

Diante dessas conceituações, a idéia de falha estaria presente na definição do que vem a ser pessoa portadora de deficiência. As pessoas que têm uma falta ou uma falha sensorial, motora ou mental, seriam pessoas com deficiência. A idéia não se apresenta tão singela. Importante frisar que a falha, a falta, não se situa no indivíduo, mas em seu relacionamento com a sociedade.

A expressão "portadora de deficiência" se apresenta, portanto, inadequada na medida que o indivíduo com deficiência apresenta dificuldades de integração com a sociedade. Sua deficiência tem mais relação com sua dificuldade de inclusão social do que com a falta sensorial, motora ou intelectual propriamente dita.

A Convenção sobre os Direitos das Pessoas com Deficiência, que ingressou no sistema constitucional brasileiro por força do Decreto-Legislativo no 186 de 09 de julho de 2008 e do Decreto de Promulgação no 6.949, de 25 de agosto de 2009, se utiliza da expressão contemporânea "Pessoa com Deficiência", mais adequada tendo em vista que a pessoa, que continua sendo o núcleo central da expressão, tem uma deficiência e não a traz contigo um deficiência, como o entendido pela expressão "portadora”.

\subsection{Tipos de Deficiência}

Existem ao todo 4 (quatro) tipos de Deficiência: deficiência física, deficiência auditiva, deficiência visual e deficiência múltipla.

De acordo com o Decreto 3.298 de, 20 de dezembro de 1999, é considerado pessoa com deficiência:

Art. $3^{\circ}$ Para os efeitos deste Decreto considera-se:

I-Deficiência - toda perda ou anormalidade de uma estrutura ou função psicológica, fisiológica ou anatômica que gere incapacidade para o desempenho de atividade, dentro do padrão considerado normal para o ser humano;

II-Deficiência permanente - aquela que ocorreu ou se estabilizou durante um período de tempo suficiente para não permitir recuperação ou ter probabilidade de que se altere, apesar de novos tratamentos; 
III-incapacidade - uma redução efetiva e acentuada da capacidade de integração social, com necessidade de equipamentos, adaptações, meios ou recursos especiais para que a pessoa portadora de deficiência possa receber ou transmitir informações necessárias ao seu bem-estar pessoal e ao desempenho de função ou atividade a ser exercida. Art.4o -É considerada pessoa portadora de deficiência a que se enquadra nas seguintes categorias:

I-deficiência física - alteração completa ou parcial de um ou mais segmentos do corpo humano, acarretando o comprometimento da função física, apresentando-se sob a forma de paraplegia, paraparesia, monoplegia, monoparesia, tetraplegia, tetraparesia, triplegia, triparesia, hemiplegia, hemiparesia, ostomia, amputação ou ausência de membro, paralisia cerebral, nanismo, membros com deformidade congênita ou adquirida, exceto as deformidades estéticas e as que não produzam dificuldades para o desempenho de funções; (grifo nosso)

II - Deficiência auditiva - perda bilateral, parcial ou total, de quarenta e um decibéis (dB) ou mais, aferida por audiograma nas freqüências de $500 \mathrm{HZ}, 1.000 \mathrm{HZ}, 2.000 \mathrm{~Hz}$ e $3.000 \mathrm{~Hz}$;

III- deficiência visual -cegueira, na qual a acuidade visual é igual ou menor que 0,05 no melhor olho, com a melhor correção óptica; a baixa visão, que significa acuidade visual entre 0,3 e 0,05 no melhor olho, com a melhor correção óptica; os casos nos quais a somatória da medida do campo visual em ambos os olhos for igual ou menor que $60 \mathrm{o}$; ou a ocorrência simult nea de quaisquer das condições anteriores;

IV - Deficiência mental - funcionamento intelectual significativamente inferior à média, com manifestação antes dos dezoito anos e limitações associadas a duas ou mais áreas de habilidades adaptativas.

O último grande censo realizado pelo IBGE, em 2010, constatou que cerca de 45 milhões de pessoas possuem algum tipo deficiência, sendo a deficiência visual a mais presente no país, afetando cerca de 29 milhões de pessoas entre o grau máximo e mínimo. A segunda deficiência mais presente entre os brasileiros é a motora, cerca de 8 milhões de brasileiros possuem alguma dificuldade de locomoção. A menor deficiência apontada no estudo foi a intelectual, que aflige mais de 2 milhões de pessoas.

\section{Pessoas com deficiência pré-constituição de 1988}

A situação de fragilidade da pessoa com deficiência sempre foi solo fértil para preconceitos e discriminações. Nesse sentido, cresce a importância de uma analise, ainda que sucinta, do preconceito com o deficiente ao longo da história.

Os relacionamentos da sociedade com as pessoas com deficiência variam de cultura para cultura, podendo, inclusive, terem reflexos de crenças e religiões. Nos anos de 1200 a 1700 d.C. as pessoas com deficiência eram vistas pela sociedade sob uma perspectiva demonização, passando por tortura física e morte. De 1800 a 1920 eram encaradas com 
defeito genético e tratadas como aberração. Já nos anos de 1930-1940 surgiu a ideia de defeito genético, devendo ocorrer a esterilização (Casimiro, 2013). No Brasil, o infanticídio em tribos indígenas era uma prática comum (Araújo, 2017).

Antes da promulgação da Constituição de 1988 a proteção as chamadas "Pessoas Portadoras de Deficiência" concentravam-se em obras caritativas, surgindo no século XIX as primeiras instituições com atenção à pessoa com deficiência.

Nesse sentido, o Instituto dos Meninos Cegos foi a primeira ação social com fins a inclusão, sendo criado em 1854. No ano de 1891 recebeu um novo nome, sendo conhecido atualmente por Instituto Benjamim Constant.

O Hospício de Pedro II foi o primeiro hospital psiquiátrico do Brasil e o segundo da América Latina, inaugurado em 1856. Já naquela época os médicos se preocupavam na reabilitação dos doentes, realizando terapia ocupacional e oficinas temáticas.

O Instituto de Surdos e Mudos foi o último instituto inaugurado. Ocorreu em 1856, na cidade do Rio de Janeiro, sendo hoje conhecido atualmente por Instituto Nacional de Educação de Surdos.

\section{A Constituição de 1988 e os direitos positivados}

A Constituição de 1988 foi um marco na equalização dos direitos fundamentais. Garantindo a igualdade e a liberdade, consagrou a dignidade da pessoa humana como pedra de toque no Estado Democrático de Direito. Nesse ínterim, a pessoa com deficiência recebeu especial tratamento constitucional, iniciando-se pela isonomia advinda pelo artigo $5^{\circ}$ da Lex Legum, que defende a igualdade sem distinção de qualquer natureza.

Com fins a efetivação de uma vida digna, a CF/88 consagrou o direito ao trabalho que, juntamente com os ditames de justiça social (art. $170 \mathrm{CF}$ ) e do princípio da busca do pleno emprego (art. 170, VIII CF), tornou-se o pilar da Ordem Econômica vigente. Como forma de combater a exploração do trabalhador e lhe assegurar melhor segurança, o legislador deixou de forma expressa na Constituição os direitos intrínsecos ao trabalhador, bem como a inserção da pessoa com deficiência neste ambiente:

CF/88 - Art. 7o São direitos dos trabalhadores urbanos e rurais, além de outros que visem à melhoria de sua condição social: 
$[\ldots]$

IV - salário mínimo, fixado em lei, nacionalmente unificado, capaz de atender a suas necessidades vitais básicas e às de sua família com moradia, alimentação, educação, saúde, lazer, vestuário, higiene, transporte e previdência social, com reajustes periódicos que lhe preservem o poder aquisitivo, sendo vedada sua vinculação para qualquer fim.

XXXI - proibição de qualquer discriminação no tocante a salário e critérios de admissão do trabalhador portador de deficiência;

Como meio de aprimorar ainda mais os direitos desses indivíduos, o legislador preocupou-se com a proteção constitucional dos direitos sociais, sobretudo os relativos à educação, com o fornecimento de educação especializada. Buscou-se, também, a sua inserção no mercado de trabalho, com vedação à distinção de salários e critérios de admissão pelo empregador, conforme demostrado pelo inciso XXXI.

Na Carta da República de 1988 a assistência social ganhou status de política pública, que juntamente com a Previdência Social e com a saúde formam o tripé da Seguridade Social, de suma importância para as pessoas com deficiência:

CF/88 - Art. 203. A assistência social será prestada a quem dela necessitar, independentemente de contribuição à seguridade social, e tem por objetivos:

[...] IV - a habilitação e reabilitação das pessoas portadoras de deficiência e a promoção de sua integração à vida comunitária; $\mathrm{V}$ - a garantia de um salário mínimo de benefício mensal à pessoa portadora de deficiência e ao idoso que comprovem não possuir meios de prover à própria manutenção ou de tê-la provida por sua família, conforme dispuser a lei.

O processo de habilitação é fornecido pelo Instituto Nacional de Seguridade Social (INSS) e ocorre quando o indivíduo está capacitado para o exercício de determinada função. Já o processo de reabilitação é um procedimento orientado a possibilitar que a pessoa com deficiência adquira, a partir da identificação de suas potencialidades laborativas, o nível suficiente de desenvolvimento profissional para reingresso no mercado de trabalho e para a participação na vida comunitária.

A habilitação e a reabilitação profissional também são abordadas de forma minuciosa pela lei $8213 / 91$ e podem incluir o fornecimento de próteses e transporte, conforme pode-se observar, ipsis litteris:

Art. 89 A habilitação e a reabilitação profissional e social deverão proporcionar ao beneficiário incapacitado parcial ou totalmente para o trabalho, e às pessoas portadoras de deficiência, os meios para a (re)educação e de (re)adaptação 
profissional e social indicados para participar do mercado de trabalho e do contexto em que vive. Parágrafo único. A reabilitação profissional compreende:

a) o fornecimento de aparelho de prótese, órtese e instrumentos de auxílio para locomoção quando a perda ou redução da capacidade funcional puder ser atenuada por seu uso e dos equipamentos necessários à habilitação e reabilitação social e profissional;

b) a reparação ou a substituição dos aparelhos mencionados no inciso anterior, desgastados pelo uso normal ou por ocorrência estranha à vontade do beneficiário;

c) o transporte do acidentado do trabalho, quando necessário.

Como se observa, o constituinte de 1988 deu norte ao tratamento do Estado no que tange a assistência diferenciada às pessoas com deficiência, o que possibilitou a equalização do país frente aos direitos adquiridos pelas leis infra-constitucionais e no âmbito do direito internacional, como será analisado a seguir.

\section{Demais dispositivos legais}

Em âmbito internacional encontramos uma série de documentos de cunho garantidor a dignidade da pessoa com deficiência, com direito a uma vida digna e igualitária. Nesse sentido - e para melhor se adequar ao tema do presente artigo - a Convenção 159 da OIT se mostra o mais relevante documento internacional na proteção dos direitos da pessoa com deficiência no mercado de trabalho. No direito interno não é diferente. Será tratado a seguir de três dispositivos importantes na promoção e defesa das pessoas com deficiência.

\section{Convenção 159-83 da OIT}

A Convenção número 159 da Organização Internacional do Trabalho ocorreu na $69^{\text {a }}$ Conferência em Genebra no dia $1^{\circ}$ de junho de 1983, tendo como escopo a valorização do empregado com deficiência no ambiente laboral, possibilitando a sua reabilitação profisssional, garantia a futuras promoções e a inserção do indivíduo em um novo mercado de trabalho, preparado e mais adequado para sua convivência.

No Brasil, a convenção de número 159 foi ratificada através do Decreto no 129, de 18 de maio de 1991 e define a pessoa deficiente como sendo aquela "cujas possibilidades de 
obter e conservar um emprego adequado e de progredir no mesmo fiquem substancialmente reduzidas devido a uma deficiência de caráter físico ou mental devidamente comprovada."

Ademais, esse dispositivo internacional surgiu com a intenção de inserir a pessoa com deficiência na sociedade, buscando a isonomia no tratamento dentro mercado de trabalho por intermédios de ações governamentais, sendo-lhes conservados os direitos mínimos, inerentes a todo cidadão, como a educação, o atendimento os requisitos de adequação as necessidades especiais, o trabalho e a previdência, todos com fins a busca do bem-estar e preservação da dignidade humana.

\subsection{Lei. $7.853 / 89$}

Foi a primeira lei dentro do ordenamento jurídico brasileiro a tratar das pessoas com deficiência, muito embora tenha sofrido modificações por novas leis. Ela dispõe sobre o apoio a pessoa com deficiência e se preocupa com a integração social, além dos chamados valores básicos de igualdade no tratamento e em oportunidades.

Consideram como valores básicos na efetiva integração social da pessoa com deficiência os valores básicos da igualdade de tratamento e oportunidade, da justiça social, do respeito à dignidade da pessoa humana, do bem-estar, conforme já mencionados pela Convenção 159-83 da OIT. Para tanto, a lei define como dever do Poder Público dar acesso ao exercício dos direitos básicos da pessoa com deficiência através da educação, com oferta gratuita e obrigatória em estabelecimento público de ensino; da saúde, com destaque ao acesso das pessoas portadoras de deficiência aos estabelecimentos de saúde públicos e privados; ao trabalho, com a promoção em emprego em setores públicos e privado para pessoas portadoras de deficiência; e outros direitos como o lazer, à previdência social e ao amparo à infância e à maternidade.

\subsection{Lei no 13.146/15}

Outro importante documento legal na proteção das pessoas deficientes é a Lei no 13.146 de julho de 2015. Esse importante dispositivo legal assegura e promove o exercício de todos os direitos e liberdades fundamentais concernentes à pessoa com deficiência. Atinente à inclusão social e o direito à cidade, tendo como base fundamental a igualdade de condições, a 
presente lei define o atendimento prioritário, em todas as circunstâncias, além de assegurar o direito à saúde no Sistema Único de Saúde (SUS), de forma universal e igualitária, à educação de forma inclusiva e a todos os níveis e aprendizados ao longo da vida, e também o direito ao trabalho, garantindo o acesso a um ambiente inclusivo e em igualdade de oportunidades.

A presente lei também trata dos demais direitos fundamentais, inerentes a todos os indivíduos, como o direito à moradia, à vida digna, à assistência e a previdência social, à mobilidade, ao acesso à justiça, política, etc.

\section{$6 \mathrm{O}$ direito ao trabalho}

O trabalho sempre esteve presente sociedade. As grandes revoluções em torno desse direito ocorreram em meio ao contexto da Revolução Mexicana, em 1917, quando foi promulgada a sua constituição, onde se encontravam presentes artigos ligados a proteção do trabalhador, como a jornada diária de 8 horas e o estabelecimento de um salário mínimo, capaz de sustentar uma família de forma digna. A Alemanha, com a Constituição de Weimar de 1919, também assegurou os direitos sociais do trabalho tendo como norte a recém criada Organização Internacional do Trabalho.

No Brasil, as conquistas vieram de forma tardia. Foi somente com o advento da Constituição de 1934 que alguns dos direitos trabalhistas hoje conhecidos foram incorporados à sociedade, como o salário mínimo, a jornada de 8 horas e o descanso semanal.

Se os direitos do trabalhador surgiram de forma tardia, os da pessoa com deficiência não ficaram atrás. Atualmente, frente às crises econômicas, as taxas de desemprego são cada vez mais alarmantes, criando castas de pessoas vivendo na situação de sub-emprego, o que aumenta ainda mais o abismo de dificuldade na absorção do mercado de trabalho das pessoas com deficiência.

As primeiras Instituições, como já visto, surgiram somente em 1854, sendo assumidas pelo governo tardiamente em 1957. Em 1961 surgiu a primeira lei sobre as Diretrizes e Bases da Educação Nacional (Lei nº 4.024/61), onde constavam, de forma tímida, o direito à educação dos “excepcionais".

$\mathrm{O}$ direito ao mercado de trabalho alcançou, inclusive, àqueles que possuíam algum tipo de retardo mental, sendo-lhes assegurado a revisão periódica de seu estado de saúde para 
uma possível habilitação, conforme presente na Declaração dos Direitos das Pessoas Mentalmente Retardadas, in verbis:

\begin{abstract}
$\S 7^{\circ}$ Sempre que pessoas mentalmente retardadas forem incapazes devido à gravidade de sua deficiência de exercer todos os seus direitos de um modo significativo ou que se torne necessário restringir ou denegar alguns ou todos estes direitos, o procedimento usado para tal restrição ou denegação de direitos deve conter salvaguardas legais adequadas contra qualquer forma de abuso. Esse procedimento deve ser baseado em uma avaliação da capacidade social da pessoa mentalmente retardada, por parte de especialistas, e deve ser submetido à revisão periódica e ao direito de apelo a autoridades superiores.
\end{abstract}

O dispositivo apresentado garante que a pessoa com doença mental passe por exames periódicos de forma a garantir a sua integração, observado seu quadro de melhora, a sociedade e, em um momento oportuno, o mercado de trabalho.

No Brasil, com o advento Constituição de 1988, foram incorporados as garantias intrínsecas às pessoas com deficiência, como a já mencionada vedação a distinção de salários entre os empregados com deficiência, que possibilitando desta maneira a efetiva garantia legal da isonomia, tão fundamental nas relações trabalhistas. A equiparação no meio de trabalho pode ser considerada um marco no combate as práticas discriminatórias no mercado de trabalho, o que corrobora de forma direta para o desenvolvimento social inclusivo e para a segurança econômica.

No que tange ao serviço público, a Constituição Federal garantiu à pessoa com deficiência cargos públicos por meio de cotas, conforme descrito em seu artigo 37:

Art. 37 - A administração pública direta e indireta de qualquer dos Poderes da União, dos Estados, do Distrito Federal e dos Municípios obedecerá aos princípios de legalidade, impessoalidade, moralidade, publicidade e eficiência e, também, ao seguinte:

[...] VIII - a lei reservará percentual dos cargos e empregos públicos para as pessoas portadoras de deficiência e definirá os critérios de sua admissão;

Embora garantido como status constitucional, o acesso a cargos públicos por pessoas com deficiência tem ficado muito distante do esperado. O setor público é o que menos preenche cota de vagas para pessoas com deficiência. Das 21,8 mil vagas ofertadas em 2017, apenas 2,3 mil foram ocupadas, o que representa um total de $11 \%$ das vagas destinadas por lei $(\mathrm{G} 1,2018)$.

O setor privado também enfrenta impasses no preenchimento das vagas. Já determinado pelo artigo 37, VIII da Constituição Federal, o percentual que deve ser reservado 
está definido pela Lei $\mathrm{n}^{\circ} 8.213$ de 1991. Esse dispositivo definiu que as empresas que possuam em seu quadro de trabalho 100 ou mais funcionários deverão, de forma progressiva, destinar o acesso as vagas por meio das cotas às pessoas com deficiência, seguindo a seguinte proporção:

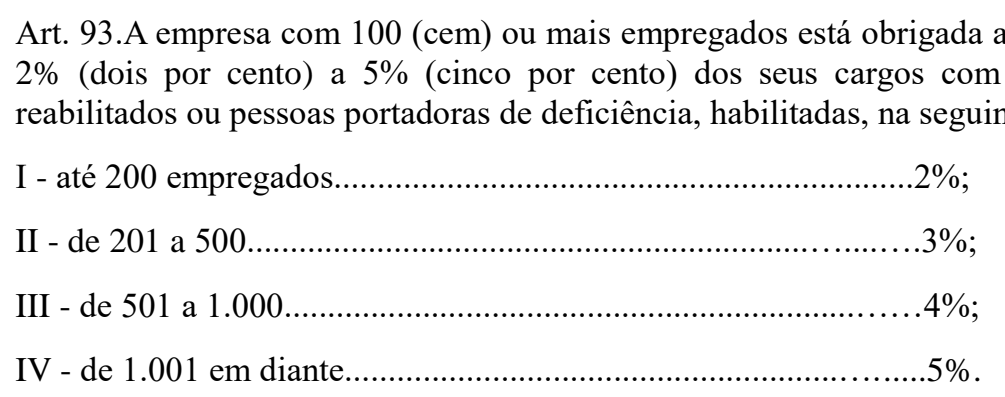

Com os importantes diplomas legais mencionados, houve uma maior responsabilidade do Estado em relação aos direitos sociais, incluindo a empregabilidade. A vedação a diferença salarial, a obrigatoriedade na reserva de vagas destinadas as pessoas com deficiência e o direito ao acesso público e gratuito a direitos como a saúde e a educação tendem a transformar a sociedade de forma justa, igualitária e inclusiva. Mas o que ocorre a vacância desses profissionais no mercado de trabalho?

\section{Os impasses no mercado de trabalho}

Muito embora tenhamos um sistema legal preparado para lidar com a assistência e a inclusão da pessoa com deficiência, o que se tem observado são cargos vagos. A qualificação é uma das razões mais pontuadas pelos empregadores, o que esbarra em outro problema comum entre as pessoas com deficiência: o acesso ao ensino superior.

Entre os anos de 2004 a 2014 o número de matrículas no ensino superior de pessoas com algum tipo de deficiência aumentou em 518\% (SIEMS-MARCONDES, 2017, p. 96). Os números são grandes, mas representam uma quantidade pequena. No ano de 2014, em específico, foram registradas 33 mil matrículas de estudantes com necessidades especiais, o que representa um total de $0,42 \%$ das matrículas realizadas naquele período, muito baixo e preocupante. 
Segundo o IBGE (IBGE, 2010), dos 45 milhões de pessoas que possuem algum tipo de deficiência, somente $17 \%$ estão a concluir ou já concluíram o Ensino Médio e apenas 6,6\% já concluíram o ensino superior.

Outro ponto importante quando se fala em empregabilidade da pessoa com deficiência está ligado à adaptação do ambiente de trabalho. Para os profissionais de recursos humanos (MERCADO, 2016) a acessibilidade representa um problema na casa dos 48\%, ficando a qualificação em $29 \%$. Já para os trabalhadores com deficiência, um dos maiores problemas encontrados no mercado de trabalho diz respeito a falta de plano de carreira.

Ademais, a acessibilidade no mercado de trabalho vai muito além da adequação do espaço físico. O preconceito continua sendo um entrave no acesso a uma vaga de trabalho. Em 2016, uma pesquisa feita com 4.300 pessoas com deficiência $(G 1,2016)$, apontou que 4 em cada 10 trabalhadores deficientes admitiam ter sofrido algum tipo de discriminação no ambiente laboral. Dos entrevistados, 9\% relataram isolamento/rejeição, 12\% afirmaram ter dificuldades para promoção e 57\% dizem terem sido vítimas de bullying.

O preconceito, a segregação e o desrespeito à dignidade das pessoas com deficiência atravessaram os séculos e ocorrem diariamente no país,ainda que de forma velada. No Brasil, $77 \%$ das pessoas com deficiência sentem que seus direitos não são respeitados $(G 1,2010)$. Somado a esse contexto social preconceituoso, a baixa qualificação das pessoas com deficiência também surge como um óbice na contração e ocupação a vagas no mercado de trabalho.

\section{A educação como política de inclusão}

O acesso à educação é fundamental ao desenvolvimento social e está estampada como direito fundamental no rol direitos e garantias individuais do artigo $6^{\circ}$ da Carta Maior. Muito embora consagrada em nossa constituição, a implementação do direito à educação especial a pessoa com deficiência, previsto no inciso III do artigo 208, ainda enfrenta dificuldades, quase sempre ligadas à recusa das instituições na execução da matrícula ou no fornecimento de uma estrutura básica necessária ao atendimento ao estudante. Dizer que a educação é um direito assegurado a todos implica em incluir no sistema básico de educação todos os alunos, independente de suas características pessoais. 
Nesse interim, a Lei 13.146 de 2015, já tratada anteriormente, dedicou um capítulo exclusivo sobre o Direito à Educação, assegurando a pessoa com deficiência o acesso a educação em todos os níveis:

Artigo 27 - A educação constitui direito da pessoa com deficiência, assegurados sistema educacional inclusivo em todos os níveis e aprendizado ao longo de toda a vida, de forma a alcançar o máximo desenvolvimento possível de seus talentos e habilidades físicas, sensoriais, intelectuais e sociais, segundo suas características, interesses e necessidades de aprendizagem. (grifo nosso)

O acesso à educação é uma condição básica ao desenvolvimento pessoal, mas por si só não é o suficiente. Há a necessidade de um espaço físico adequado à deficiência do aluno, um corpo docente preparado para educação e desenvolvimento conjunto e, por fim, o investimento do Governo Federal, em parceria com os demais entes, em todas as áreas da educação especial, da estrutura ao corpo docente, do material à alimentação.

RECURSO EXTRAORDINÁRIO MATÉRIA FÁTICA INVIABILIDADE DESPROVIMENTO DO AGRAVO. 1. O Tribunal de origem confirmou o entendimento do Juízo quanto ao direito do menor a vaga em escola estadual especial de ensino, considerada a necessidade de que é portador surdez bilateral e a falta de estrutura adequada das unidades regulares.. No extraordinário cujo tr nsito busca alcançar, o recorrente aponta violado o artigo 5o, $\S 30$, da Constituição Federal. Sustenta que na Convenção de Nova Iorque sobre os Direitos das Pessoas com Deficiência, com estatura de emenda constitucional, porque ratificada pelo Brasil, está prevista inserção do aluno defíciente no sistema regular. 2. A recorribilidade extraordinária é distinta daquela revelada por simples revisão do que decidido, na maioria das vezes procedida mediante o recurso por excelência a apelação. Atua-se em sede excepcional à luz da moldura fática delineada soberanamente pelo Tribunal de origem, considerando-se as premissas constantes do acórdão impugnado. A jurisprudência sedimentada é pacífica a respeito, devendo-se ter presente o Verbete no 279 da Súmula do Supremo: Para simples reexame de prova não cabe recurso extraordinário. Eis os fundamentos do acórdão recorrido: Portanto, conquanto não se olvide acerca da relev ncia da argumentação veiculada pelo Estado de Minas Gerais no sentido de que a educação, objetivando maior inclusão, deve, como regra, ser prestada junto ao sistema regular de ensino, necessário adentrar às particularidades do quadro clínico do menor e averiguar a medida se afigura mais proveitosa, ou seja, qual vai ao encontro do seu melhor interesse. Segundo relatório médico acostado a f. 19 dos autos o menor J.W.R.O. tem perda auditiva profunda e bilateral, tendo o próprio médico filiado ao SUS sugerido a inclusão em escola especial. Diante do referido quadro, necessário destacar a regra que com tanto afinco se apega o Estado de Minas Gerais, segundo a qual "Entende-se por educação especial, para os efeitos desta Lei, a modalidade de educação escolar, oferecida preferencialmente na rede regular de ensino, para educandos portadores de necessidades especiais", (art. 58, Caput, da Lei 9.394/96, de Diretrizes e Bases da Educação). Diante do texto normativo aduzido cumpre destacar que semanticamente e, principalmente, juridicamente, ao termo "preferencialmente", só pode ser emprestado um sentido, qual seja, aquele de indicar que a medida será adotada quando se mostrar consoante ao melhor interesse do menor e não para facultar ao ente público, na seara dos direitos fundamentais sociais, prestações positivas menos onerosas, em escancarada violação à proibição do retrocesso social no que diz respeito aos direitos fundamentais. [...] Ora, na 
escola especial, decerto, referida diretriz será observada. Por isto, o pleito autoral apenas perderia força acaso demonstrado que a educação regular, nos moldes que se propõe a oferecer o Estado de Minas Gerais, viabilizaria a alfabetização na linguagem adequada às suas limitações, tal qual a existência de professor de língua de sinais, (art. 24, 4, da Convenção das Pessoas com Deficiência), providência nem de longe demonstrada pelo Estado de Minas Gerais que prefere, levianamente, adulterar o conteúdo sem ntico da expressão preferencialmente utilizada pelo legislador federal, para emprestar-lhe o sentido de óbice legal à existência de escolas especiais. As razões do extraordinário partem de pressupostos fáticos estranhos à decisão atacada, buscando-se, em última análise, o reexame dos elementos probatórios para, com fundamento em quadro diverso, assentar a viabilidade do recurso. 3. Conheço do agravo e o desprovejo. 4. Publiquem. Brasília, 30 de maio de 2016. Ministro MARCO AURÉLIO Relator. ${ }^{4}$

O caso acima apresentado ilustra aquilo defendido pelo texto constitucional, mais precisamente no artigo 208, onde é do obrigação do Estado o atendimento educacional especializado. No presente julgado o Estado de Minas Gerais negou vaga em escola especializada sob o entendimento de que o texto constitucional transferiria ao ente público a melhor decisão, onde, se baseando em suas possibilidades financeiras, ofereceria a aludida vaga, atentando-se as prestações menos onerosas para ele. Esse entendimento foi desfeito pelo STF, alegando o Ministro Marco Aurélio que a expressão "preferencialmente" estaria ligada às necessidades do indivíduo com deficiência, com fins a atender as suas demandas e não ligado a prestação menos onerosa ao Estado.

\section{Liberdade, igualdade e deficiência}

A existência da liberdade da pessoa com deficiência tem vinculação direta com a suas limitações. Liberdade representa aquilo que o indivíduo é, seus anseios. A vulnerabilidade é determinante para distinguir quem possui e quem é privado da liberdade. Em A Ideia de Justiça, Hannah Arendt aprecia o valor da liberdade por duas razões (2011, p. 262):

Em primeiro lugar, mais liberdade nos dá mais oportunidade de buscar nossos objetivos - tudo aquilo que valorizamos. Ela ajuda, por exemplo, em nossa aptidão para decidir viver como gostaríamos e para promover os fins que quisermos fazer avançar. [...] Em segundo lugar, podemos atribuir import ncia ao próprio processo de escolha. Podemos, por exemplo, ter certeza de que não estamos sendo forçados a algo por causa de restrições impostas por outros. (grifo do autor)

4. STF - ARE: 966316 MG - MINAS GERAIS 1233027-44.2012.8.13.0024, Relator: Min. MARCO AURÉLIO, Data de Julgamento: 30/05/2016, Data de Publicação: DJe-113 03/06/2016. 
Nesse sentido, um indivíduo que não tem acesso ao trabalho, meio de subsistência e de integração, não tem liberdade. O sujeito privado do acesso a um espaço público, como praias, teatros e universidades, não tendo seu processo de escolha respeitado, é refém de uma barreira social, logo, não tem liberdade. O aluno que vê a sua preferencia ser alterada de forma leviana pelo Estado para melhor se adequar a seu poder de mando, não tem liberdade.

A liberdade depende, inclusive, de outros fatores, "em particular da organização social, incluindo a saúde pública, a garantia de assistência médica, a natureza da escolarização e da educação, o grau de coesão e harmonia sociais, e assim por diante" (Arendt, 2011, p. 261).

Um sujeito só é realmente livre quando goza da igualdade em todos seus aspectos. Um homem privado de suas capacidades visuais é, frente ao Estado, um sujeito de direitos e deveres, mas tem sua igualdade tolida quando o meio em que circula não é adaptado a suas necessidades, portanto, não é um homem livre e igual. Há uma desigualdade de liberdade, explica Rawls (1977, p.220), quando "uma categoria de pessoas tem uma liberdade maior do que outra, ou a liberdade é menos extensiva do que deveria ser".

A liberdade extensiva, conforme mencionado por Rawls, deveria alcançar os indivíduos de forma a equalizar todas as possíveis peculiaridades existentes dentro de uma comunidade, ainda que essas estejam relacionadas a determinados sujeitos e suas limitações. Dessa forma, a liberdade deve ser responsável pela diminuição da fronteira da desigualdade, deve ser emancipadora, construindo uma sociedade de pessoas livres, iguais e que colaboram entre si.

\section{CONCLUSÕES}

O Brasil é referência em leis com fins à proteção da pessoa com deficiência. Embora tenha-se feito muito para assegurar às pessoas com deficiência uma vida igualitariamente digna a dos demais indivíduos, o que ocorre é um duplo retrocesso. Por um lado, temos a baixa fiscalização do ambiente de trabalho, inexistência de adequação do ambiente e cumprimento da lei de cotas. Por outro, o avanço do preconceito e da discriminação, enraizados na sociedade. Aliado a esses problemas estruturais, temos o baixo acesso da pessoa com deficiência ao ensino básico e de qualidade. Isso ocorre não só no início da vida, mas também, em um segundo momento, no ensino superior, sendo causados por diversos fatores, 
como acessibilidade, locomoção e incentivo por meio de políticas públicas mais eficientes. Desta maneira, a vacância no mercado de trabalho pelas pessoas com algum tipo de deficiência surgem, também, pela não qualificação a função oferecida.

A liberdade do homem é a sua identificação dentro de um estado democrático. De nada adianta uma legislação farta no incentivo de políticas inclusivas e forte no combate a desigualdade se os meios garantidores da justiça enfrentarem barreiras no processo de efetivação. O que se espera futuramente é uma sociedade mais aberta ao diferente, um governo mais rígido na fiscalização e inovação de políticas sociais e, por fim, um ambiente de trabalho sadio, onde a inclusão e a aceitação sejam a regra para o combate de todo e qualquer tipo de preconceito

\section{REFERÊNCIAS}

ARANHA, M.S.F. Paradigmas da relação da sociedade com as pessoas com deficiência. Revista do Ministério Público do Trabalho, Ano XI, n. 21, p. 160-173, 2001. Disponível em: cape.edunet.sp.gov.br/textos/textos/11.doc. Acesso em: 13 nov. 2019 MAZZOTTA. Marcos José da Silveira; D’Antino, Maria Eloísa Famá. Inclusão Social de Pessoas com De ciências e Necessidades Especiais: cultura, educação e lazer. Scielo: São Paulo, v.20, n.2, p.377-389, 2011. Disponível em <http://www.scielo.br/pdf/sausoc/v20n2/10.pdf> Acesso em 02 nov 2019.

SANTOS, Maria da Conceição dos. Pessoa com deficiência física, necessidades de saúde e integralidade do cuidado: análise das práticas de reabilitação no SUS. Tese ( Doutorado em Medicina) - Universidade de São Paulo. São Paulo: FM-USP, 2017.

\section{REFERÊNCIAS BIBLIOGRÁFICAS}

ARAUJO, Ana Paula Valentim. Infanticídio indígena e a postura do estado brasileiro. Revista Arquivo Brasileiro de Educação. Belo Horizonte, v. 5, n.10. Disponível em $<$ http://periodicos.pucminas.br/index.php/arquivobrasileiroeducacao/article/view/ P.23187344.2017v5n10p85/12943> Acesso em 15 mar. 2019. ARAUJO, Luiz Alberto David. A proteção constitucional das pessoas com deficiência. ed. Brasília: Corde, 2001.

BRASIL. Lei. 7.853/89, de 24 de outubro de 1989. Diário Oficial da União, Brasília, DF, out 1989. Disponível em: <http://www.planalto.gov.br/ccivil_03/leis/L7853.htm>. Acesso em: 05 out 19.

Rev. Revista de Direitos Fundamentais nas Relações do Trabalho, Sociais e Empresariais| e-ISSN: 2525-9903| Evento Virtual| v. 6 | n. 1 | p. 1-18 | Jan/Jun. 2020 
BRASIL. Decreto Lei. 129, de 22 de maio de 1991. Brasília, DF, maio 1991. Disponível em: <http://www.planalto.gov.br/ccivil_03/decreto/1990-1994/D0129.htm>. Acesso em: 05 nov 19.

BARBOZA, Anderson. Discriminação é a pior violência no mercado de trabalho, afirma jovem com deficiência. Gl, Sergipe, maio. 2017. Disponível em $<$ https://g1.globo.com/se/sergipe/noticia/discriminacao-e-a-pior-violencia-no-mercadodetrabalho-afirma-jovem-com-deficiencia.ghtml> Acesso em 08 nov 19.

COM nova margem de corte, IBGE constata $6,7 \%$ de pessoas com deficiência no Brasil. Estadão, jun. 2018. Disponível em <https://educacao.estadao.com.br/blogs/educacao-eetc/com-nova-margem-de-corteibgeconstata-67-de-pessoas-com-deficiencia-no-brasil/> Acesso em 05 nov. 2019.

RAWLS, John. Uma Teoria da Justiça. Lisboa: Editorial Presença, 1993.

LOPES, Gustavo Casimiro. El prejuicio contra la persona con discapacidad a lo largo de la historia. Revista EFDeportes, n. 176. Disponível em <http://www.efdeportes.com/efd176/odeficiente-ao-longo-da-historia.htm>. Acesso em 05 nov. 2019.

MILANEZI, Larissa. Acessibilidade e deficiência: qual a relação com as políticas públicas?. Poletize, São Paulo, mar. 2017. Disponível em <https://www.politize.com.br/acessibilidade-eo-direito-das-pessoas-com-deficiencia/> Acesso em 05 nov. 2019..

NETO, João Gomes Dutra. Evolução histórica do tratamento conferido às pessoas portadoras de necessidades especiais pelo ordenamento jurídico brasileiro. Jus Navigandi, Teresina, jun. 2016. Disponível em <https://jus.com.br/artigos/29205/evolucao-historica-dotratamentoconferido-as-pessoas-portadoras-de-necessidadesespeciais-pelo-ordenamentojuridicobrasileiro> Acesso em 08 nov. 2019.

OLIVEIRA, Filipe. Para RH, falta de acessibilidade é maior entrave para contratar pessoa com deficiência. Folha de São Paulo, São Paulo, 21 set. 2015. Mercado. Disponível em $<$ https://www1.folha.uol.com.br/mercado/2016/10/1825694-falta-de-acessibilidade-emaiorentrave-para-contratar-pessoa-com-deficiencia.shtml $>$ Acesso em 09 nov. 2018. PIRES, Bruno Laurito. O Princípio da Igualdade de Tratamento aplicado nas relações de trabalho. Jusbrasil, Nov 2013. Disponível em <https://blauritopires.jusbrasil.com.br/artigos/113719154/ o-principio-da-igualdade-detratamento-aplicado-nas-relacoes-de-trabalho $>$ Acesso em 08 nov 18 RAWLS, John. Uma teoria da justiça. Tradução de Almiro Pisetta; Lenita M. R. Esteves. São Paulo: Martins Fontes, 1997.

SEN, Amartya. A ideia de justiça. Tradução de Denise Bottmann. São Paulo: Companhia das Letras, 2011.

SIEMS-MARCONDES, Maria Edith Romano. Estudantes com deficiência no ensino superior: trajetórias escolares, acesso e acessibilidade. Revista Ciência da Informação: Brasília, DF, v.11 n.1, p.94-104, jul./dez. 2017. Disponível em 
<http://webcache.googleusercontent.com/search?q=cache:JHT3YUvCpOgJ:revista.ibict.br /inclusao/article/view/4083/3594+\&cd=2\&hl=pt-BR\&ct=clnk\&gl=br\&client=safari $>$ Acesso em 26 jul 2020.

SILVA, Luzia Gomes da. Portadores de deficiência, igualdade e inclusão social. Revista Âmbito Jurídico, Rio Grande, n. 95. Disponível em: <http://www.ambito-juridico.com.br/site/ index.phpn_link=revista_artigos_leitura\&artigo_id= 10839 >Acesso em 06 nov. 2019.

THOMÉ, Clarissa. No País, 77\% dos portadores de deficiência se sentem desrespeitados. Estadão, São Paulo, dez. 2010. Disponível em <https://www.estadao.com.br/noticias/geral,no-pais-77-dos-portadores-de-deficienciasesentem-desrespeitados-imp-,653356> Acesso 12 nov. 2019. 